\title{
Bus Rapid Transit-oriented Development: A Review of Built Environment Qualities Potentially Triggering Bus Rapid Transit Passengers' Modal Shift
}

\author{
Lutfi Prayogi \\ Department of Architecture \\ Universitas Muhammadiyah Jakarta \\ Jakarta, Indonesia
}

\author{
Dedi Hantono \\ Department of Architecture \\ Universitas Muhammadiyah Jakarta \\ Jakarta, Indonesia
}

\begin{abstract}
This article explores some built environment qualities that are potentially considered by bus rapid transit (BRT) passengers when shifting their mode of transport from driving their private vehicle to taking the BRT system for the same kind of trip. The qualities are explored as part of an attempt to design an appropriate BRT passengers' modal shift evaluation. The BRT passengers' modal shift evaluation is to be carried out to synthetize some BRT passengers-friendly built environment principles under transit-oriented development framework. This article was written through a literature review on articles exploring transit passengers experience during travelling to and from transit stops. It is found that a number of built environment qualities experienced during travelling to and from transit stops are potentially considered by BRT passengers when shifting their mode of transport. The built environment qualities are route distance, directness, safety and comfort.
\end{abstract}

Keywords: Bus rapid transit, passengers, modal shift, built environment, consideration

\section{INTRODUCTION}

Transit-oriented development (TOD) is a concept that has been much discussed lately. It has been discussed and developed as an urban development concept alternate to urban sprawl and claimed as not having drawbacks urban sprawl has. [1-5] There has been much discussion on the goals, principles and components of TOD. [3, 6] There has also been much discussion on relatively successful cases of TODs. [3-7] From those discussions, it can be inferred that there are at least two integral components of TOD. The first one is the operation of one or more rapid transit system in an area that trigger and orient the development of the area. The second one is the development of the area that is planned and designed in a way supporting the operation of the transit system.

One approach on evaluating the conduct of TOD in an area is by evaluating the respective area residents' modal shift from driving their private vehicles to taking transit for the same kind of trip. [8-9] This approach is relevant with some common TOD goals and principles agreed by academics and practitioners. [9] Such modal shift may be triggered by transit system-internal factors (i.e. qualities of the transit system) and transit system-external factors (i.e. qualities of the built environment around the transit system). [10] In regards of the later factors, there has been much discussion on how the qualities and design of an area triggers the use and operation of a transit system. [11-27] However, very little of those discussions are directed to exploring the transit passengers' modal shift. For instance, very little of those discussions are directed to quantifying the magnitude of the passengers' modal shift or to elaborating the passengers' experience of modal shifting.

This article intends to serve as a preliminary research on exploring the built environment qualities that trigger residents shifting their mode of transport. This article explores some built environment qualities that are potentially considered by transit passengers when shifting their mode of transport. The qualities potentially considered are explored before the empirical evaluation of the transit passengers' modal shift being carried out so that the empirical evaluation can be carried out validly, accurately and effectively.

Meanwhile, bus rapid transit (BRT) is also a concept that has been much discussed lately. BRT is generally understood as an enhanced bus service having a level of service in par with rail-based transit while having capital and operational cost lower than rail-based transit. [28-33] It has been much developed and built worldwide lately due to its operation flexibility and simplicity, service efficiency and low cost. [28, 31, 32] BRT systems have been built prevalently in cities of countries wanting to provide mass rapid transit services but having limited resources. [28, 31]

BRT has been recognized compatible to be built in conjunction with TOD. There has been a number of recorded cases where the operation of BRT systems triggered TODs around the systems. [34] Considering the unique features of BRT and BRT's compatibility to be built in conjunction with TOD, this article focuses on built environment qualities potentially considered by BRT passengers when shifting their mode of transport.

\section{METHODS}

This research intends to answer the following question, "What are the built environment qualities potentially considered by bus rapid transit (BRT) system passengers when they shift their mode of transport from driving their private vehicles to taking the BRT system?” By answering the question, this article intends to provide a knowledge base for the evaluation of the built environment around BRT system through passengers' point of view. The result of such 
evaluation complemented with the result of BRT passengers' modal shift magnitude evaluation will be able to help better explaining the conduct of transit-oriented development (TOD) presumably occurring around the BRT system. Furthermore, the result of both evaluations will be able to help better explaining the two integral components of TOD: the operation of transit system that trigger and orient the development of the area and the development of the area that is planned and designed in a way supporting the operation of the transit system.

This research utilizes one loose working hypothesis, that is the series of built environment experienced during travelling to and from the BRT stops influence BRT system passengers to shift their mode of transport. This hypothesis was developed by considering Ma and Cao's work [35] which concluded that objective built environment affects one's travel behavior through the built environment's influence on his/her perception. They found that the mentioned phenomenon applies to transit passengers.

Literature review is chosen as the method for this research. It is considered appropriate for revealing the state of the art of the issue mentioned in the research question (i.e. the built environment qualities that are potentially considered by bus rapid transit (BRT) system passengers when they shift their mode of transport). By considering the utilized hypothesis, the literature review was originally directed to looking for records on passengers' experiences when travelling to and from transit stops and explanation about those experiences.

\section{RESULTS AND DISCUSSIONS}

\section{A. Perceived Distance To and From BRT Stops}

We may infer from a lot of works $[11,14,15,21,22,24$, $25,27]$ that the distance to and from transit stops perceived by one significantly influences his/her decision on taking or not taking the transit system. The perceived distance one perceives is crafted from and influenced by a number of things, including actual distance, population density, land use diversity and street network pattern. Actual distance is a significant ingredient of perceived distance. However, as will be elaborated further, a number of things are perceived by one, making the perceived distance sometimes different from the actual distance.

Chakrabarti [11], Jun et. al. [15], Park et. al. [22], Shan et. al. [24] and Sung et. al. [27] highlighted the different potential passenger figures of various transit stops situated in areas having different population density. In general, transit stops situated in areas having higher population density have higher potential passenger figures than transit stops situated in areas having lower population density. It can be inferred from their works that transit stops attract more passengers from among people living close to the stops than from among people living far from the stops. It can also be inferred from their works that transit passengers prefer to travel short distance to and from transit stops. In regards of the actual distance travelled by pedestrian to and from transit stops, Jun et. al. [15] and Sung et. al. [27] summarized some walkable distances of various societies around the world. The walkable distance to and from transit stops varied from 200 to $800 \mathrm{~m}$. The walkable distance to and from bus stops tend to be lower than to and from rail stations. Jun et. al. [15] termed the walkable distance as pedestrian catchment area (PCA).
Meanwhile, Jun et. al., [15] Park, et. al. [22] and Shyr et. al. [25] highlighted the different potential passenger figures of various transit stops situated in areas having different land use diversity. In general, transit stops situated in areas having more diverse land use have higher potential passenger figures than transit stops situated in areas having more uniformed land use. Population density and land use diversity maybe affecting the perceived distance travelled by transit passengers to and from the transit stops. Population density and land use diversity maybe affecting the experience of the travel. For instance, walking through a route along with other pedestrians may seem shorter than walking through the same route alone. Another instance, walking through a route and stopping at places along the route for doing daily activities (e.g. buying groceries, paying bills, picking kids from school, etc.) may seem shorter than walking through the same route solely for travelling to or from transit stop. Meanwhile, it is worth to note that findings of Li's et. al. [17] and Sung's et. al. [27] studies contradict findings of Jun's et. al. [15] and Park's et. al. [22] studies. Li and Sung et. al. found that potential passenger figures of various transit stops situated in areas having different land use diversity are not significantly different.

Garcia-Palomares [14] and Ramezani [21] showed that a number of various transit stops surrounded by different street patterns have different potential passenger figures. GarciaPalomares mentioned three different street network patterns surrounding transit stops that that generate different potential passenger figures for the transit stops: irregular, orthogonal and station-oriented. He found that station-oriented street network pattern surrounding a transit stop tends to generate the most potential passenger for the transit stop, followed by orthogonal and irregular street network patterns. Meanwhile, Ramezani [21] found that transit stops that are surrounded by finely penetrating local street network tend to attract more people to use the transit. We may infer from these works that transit passengers perceive the various different street network pattern around the transit stops, react differently towards them and consider them when deciding to take or not to take the transit system.

Figure 1 shows examples of irregular street network surrounding a transit stop and examples of routes one must travel to and from the transit stop. Figure 2 shows examples of orthogonal street network and station-oriented street network surrounding a transit stop and examples of routes one must travel to and from the transit stop. From the two figures we may see that a station-oriented street network surrounding a transit stop offers the most direct routes to and from the transit stop. Figure 3 shows examples of local street networks with different penetrability. We may see that the area within circle 1 is finely penetrated by the local street network. The area is more finely penetrated by the local street network than areas within other circles. One can travel within circle 1 from places to places more directly and with less need to detour than within other circles. We may infer from Garcia-Palomares' [14] and Ramezani's [21] works that transit passengers tend to prefer having the most direct route to and from transit stops; they don't prefer having to turn multiple times along the route or to detour. 


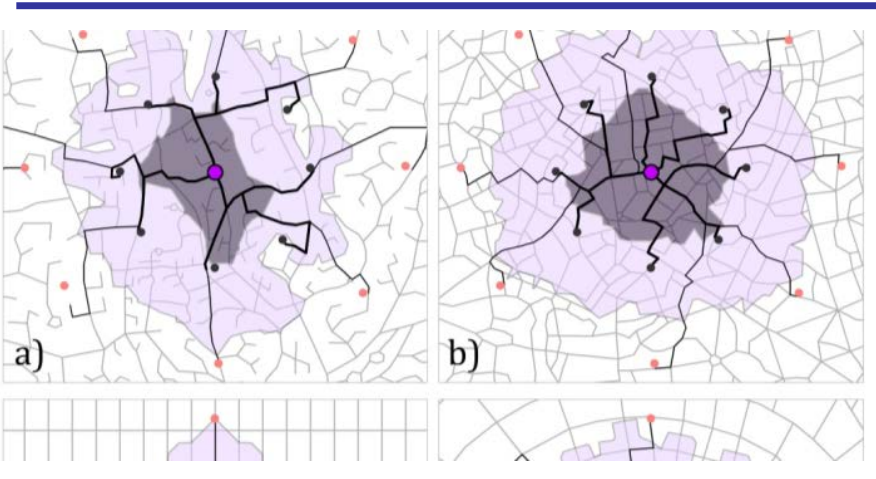

Figure 1 Examples of irregular street network surrounding a transit stop. Source: Garcia-Palomares (2018)[14]

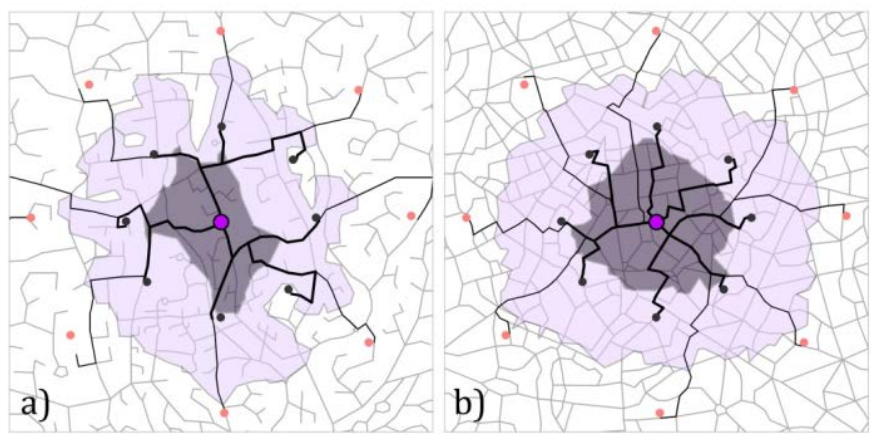

Figure 2 Left image: An example of orthogonal street network surrounding a transit stop. Right image: An example of station-oriented street network surrounding a transit stop. Source: Garcia-Palomares (2018)[14]

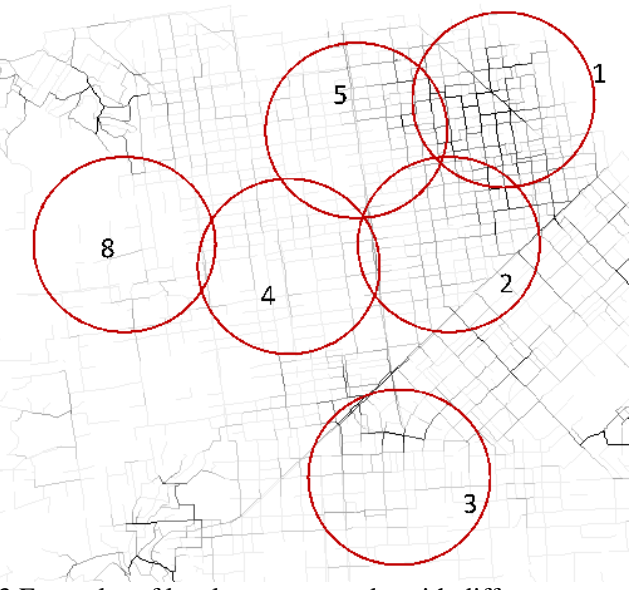

Figure 3 Examples of local street networks with different penetrability. Source: Ramezani (2018)[21], edited by author

\section{B. Perceived Safety and Comfort on Routes To and From BRT Stops}

Estupinan and Rodriguez, [13] Mohanty et. al., [19] Ramezani et. al. [20, 21] and Renne et. al. [23] highlighted the significant influence pedestrian and cyclist infrastructures around transit stops have towards the potential passenger figure of the transit system. The mentioned pedestrian infrastructure includes sidewalk and road crossing, while the mentioned cyclist infrastructure includes cycle path and cycle storage. In their works, safety and comfort for user of those facilities is highlighted. We may infer from the mentioned works that transit passengers prefer to travel to and from transit stops by utilizing safe and comfortable pedestrian and cyclist infrastructure. Meanwhile, it is worth to note Ramezani's et. al.
[21] findings that residents of different cities tend to perceive safety and comfort differently, making the pedestrian and cyclist infrastructures' safety and comfort assessment different for different societies.

Furthermore, in regards of pedestrian infrastructure, safety features include sidewalk separation and protection from vehicular traffic, day and night illumination, public observation ('eyes on the street') and road crossing priority over and safety from crossed vehicular traffic. Comfort features of pedestrian infrastructure include proper width, shading and shelter from undesirable weather, cleanliness of sidewalk and surrounding buildings and informative signages to and from transit stops. In regards of cyclist infrastructure, safety and comfort features include cycle path separation and protection from motorized vehicular traffic, priority right of way at road intersections and secured cycle storage at transit stops.

Jun et. al. [15] and Sung et. al. [27] highlighted the significant influence intermodal facilities at transit stops have towards the potential passenger figure of the transit system. Closely located different transit system stops having proper intermodal facilities attract more passengers than distantly located different transit system stops not having proper intermodal facilities. Issues of intermodal facilities include transit stops arrangement and informative signages. We may infer from the mentioned works that transit passengers prefer to be able to transfer from one to other transit system by only having short walk through comfortable routes within navigable area.

\section{CONCLUSION}

We may conclude from sub-section A of section III that there are some built environment qualities potentially considered by bus rapid transit (BRT) passengers when shifting their mode of transport from driving their private vehicles to taking the BRT system, that are population density, land use diversity and street network pattern. We also may conclude from sub-section B of section III that BRT passengers may also consider safety and comfort of pedestrian and cyclist infrastructures around the BRT stops and compactness and navigability of intermodal facilities. These issues need to be evaluated through a BRT passengers' modal shift evaluation in order to better understand the conduct of transit-oriented development (TOD) presumably occurring around the BRT system. A quantitative revealed-preference (RP) interview to the BRT system passengers will be appropriate for acquiring the general view of the TOD conduct. However, a qualitative RP focus group discussion (FGD) with the passengers will be more appropriate for acquiring more thorough opinions regarding the fine details of the built environment. Information on the fine details of the built environment considered by BRT passengers when shifting their mode of transport will be a worthy guidance for designing built environment that trigger it residents to shift to taking transit, in which the modal shift is expected in a TOD.

\section{ACKNOWLEDGMENT}

This research was funded by Universitas Muhammadiyah Jakarta under Hibah Penelitian Unggulan Lembaga Penelitian dan Pengabdian Masyarakat 2018. 


\section{REFERENCES}

[1] R. Bruegmann, Sprawl: A Compact History. Chicago, IL: University of Chicago Press, 2005.

[2] R.W. Burchell, G. Lowenstein, W. Dolphin, C. Galley, A. Downs, Costs of Sprawl - 2000. Washington, DC: National Academy Press, 2002.

[3] R. Cervero, C. Ferrell, S. Murphy, Transit-oriented Development and Joint Development in the United States. Washington, DC: Federal Transit Administration, 2002.

[4] R. Cervero, The Transit Metropolis: A Global Inquiry. Washington, DC: Island Press, 1998

[5] H. Suzuki, R. Cervero, K. Iuchi, Transforming Cities with Transit: Transit and Land-use Integration for Sustainable Urban Development. Washington, DC: World Bank Group, 2013.

[6] Institute for Transport and Development Policy, The TOD Standard. New York, NY: Institute for Transport and Development Policy, 2017.

[7] P. Calthorpe, The Next American Metropolis: Ecology, Community, and the American Dream. New York, NY: Princetion Architectural Press, 1993.

[8] L. Prayogi, Y. Sari, "The approaches on assessing the influence of a bus rapid transit system on urban development.” Article in press.

[9] L. Prayogi, "Bus rapid transit oriented development: A review of modal shift triggering ability of a bus rapid transit (BRT) system," Proceeding of International Seminar and Workshop of Urban Planning and Community Development, pp. 75-84, December 2017.

[10] L. Prayogi, A. F. Satwikasari, "Bus rapid transit-oriented development: An identification of bus rapid transit system passengers' modal shift considerations." Article in press.

[11] S. Chakrabarti, "How can public transit get people out of their cars? An analysis of transit mode choices for commute trips in Los Angeles," Transport Policy, 54, pp. 80.89, 2017. doi: 10.1016/j.tranpol.2016.11.005

[12] G. Currie, A. Delbosc, "Understanding bus rapid transit route ridership drivers: An empirical study of American BRT systems," Transport Policy, 18(5), pp. 755-764, 2011. doi: 10.1016/j.tranpol.2011.03.003

[13] N. Estupinan, D.A. Rodriguez, "The relationship between urban form and station boardings for Bogota's BRT,” Transportation Research Part A, 42, pp. 296-306, 2008. doi: 10.1016/j.tra.2007.10.006

[14] J.C. García-Palomares., J. Sousa Ribeiro, J. Gutiérrez, T. Sá Marques, 2018. "Analysing proximity to public transport: The role of street network,” Boletín de la Asociación de Geógrafos Españoles, 76, pp. 102130, 2018. doi: 10.21138/bage.2517

[15] M.J. Jun, K.C. Choi, J.E. Jeong, K.H. Kwon, H.J. Kim. "Land use characteristics of subway catchment areas and their influence on subway ridership in Seoul,” Journal of Transport Geography, 48, pp. 30-40, 2015. doi: 10.1016/j.jtrangeo.2015.08.002

[16] Hensher, D.A., Li, Z, "Ridership drivers of bus rapid transit systems", Transportation, 2012. doi: 10.1007/s11116-012-9392-y

[17] X. Li, Y. Liu, Z. Gao, D. Liu, "Linkage between passenger demand and surrounding land-use patterns at urban rail transit stations: A canonical correlation analysis method and case study in Chongqing”, International Journal of Transportation Science and Technology, 5, pp. 10-16, 2016. doi: 10.1016/j.ijtst.2016.06.002.

[18] Y. Lu, G. Sun, C. Sarkar, Z. Gou, Y. Xiao, "Commuting mode choice in a high-density city: Do land-use density and diversity matter in Hong Kong?”. International Journal of Environmental Research and Public Health, 15, pp. 920-932, 2018. doi: 10.3390/ijerph15050920
[19] S. Mohanty, S. Bansal, K. Bairwa, "Effect of integration of bicyclist and pedestrians with transit in New Delhi," Transport Policy, 57, pp. 31-40, 2017. doi: 1 0.1016/j.tranpol.2017.03.019

[20] S. Ramezani, B. Pizzo, E. Deaking, "An integrated assessemnet of factors affecting modal choice: Towards a better understanding of the causal effects of built environment," Transportation, 40(5), pp. 1-37, 2017. doi: 10.1007/s11116-017-9767-1

[21] S. Ramezani, B. Pizzo, E. Deaking, "Determinants of sustainable mode choice in different socio-cultural contexts: a comparison of Rome and San Fransisco," International Journal of Sustainable Transportation, 2018. doi: 10.1080/15568318.2017.1423137

[22] K. Park, R. Ewing, B.C. Scheer, G. Tian, "The impacts of built environment characteristics of rail station areas on household travel behavior," Cities, 74, pp. 277-283, 2018. doi: 10.1016/j.cities.2017.12.015

[23] J.L. Renne, S. Hamidi, R. Ewing., "Transit commuting, the network accessibility effect, and the built environment in station areas across the United States,” Research in Transport Economics, 60, pp. 35-43, 2016. doi: 10.1016/j.retrec.2017.02.003

[24] Q. Shen, P. Chen, H. Pan, "Factors affecting car ownership and mode choice in rail transit-supported suburbs of a large Chinese city," Transportation Research Part A, 94, pp. 31-44, 2016. doi: 10.1016/j.tra.2016.08.027

[25] O.F. Shyr, D.E. Andersson, Y.H. Cheng, Y.H. Hsiao, "What explains rapid transit use? Evidence from 97 urbanized areas," Transportation Research Part A, 100, pp. 162-169, 2017. doi: 10.1016/j.tra.2017.04.019

[26] A. Singhal, C. Kamga, A. Yazici, "Impact of weather on urban transit ridership,” Transportation Research Part A, 69, pp. 379-391, 2014. doi: 10.1016/j.tra.2014.09.008

[27] H. Sung, K. Choi, S. Lee, S.H. Cheon, "Exploring the impacts of land use by service coverage and station-level accessibility on rail transi ridership,” Journal of Transport Geography, 36, pp. 134-140, 2014. doi 10.1016/j.jtrangeo.2014.03.013

[28] T. Deng , M. Ma, J. Wang, "Evaluation of bus rapid transit implementation in China: Current performance and progress,” Journal of Urban Planning and Development, 139(3), pp. 226-234, 2013. doi 10.1061/(ASCE)UP.1943-5444.0000150

[29] T. Deng, J.D. Nelson, "Recent developments in bus rapid transit: A review of the literature,” Transport Reviews, 31(1), pp. 69-96, 2011. doi: 10.1080/01441647.2010.492455

[30] D.A. Hensher, T.F. Golob, "Bus rapid transit systems: A comparative assessment," Transportation, 35(4), pp. 501-518, 2008. doi 10.1007/s11116-008-9163-y

[31] D. Hidalgo, P. Graftieaux, "Bus rapid transit systems in Latin America and Asia: Results and difficulties in 11 cities,” Transportation Research Record, 2072, pp. 77-88, 2008. doi: 10.3141/2072-09

[32] L. Wright, in Deutsche Gesellschaft fur Technische Zusanmmenarbeitr (GTZ) GmbH (Ed.), Mass transit options. Eschborn: Deutsche Gesellschaft fur Technische Zusanmmenarbeitr (GTZ) GmbH, 2002.

[33] L. Wright, W. Hook, Bus rapid transit planning guide (3rd edition ed.). New York, NY: Institute for Transportation and Development Policy, 2007.

[34] H. Suzuki, R. Cervero, K. Iuchi. Transforming cities with transit: Transit and land-use integration for sustainable urban development. Washington, DC: World Bank Group, 2013.

[35] L. Ma, J. Cao, "How perceptions mediate the effects of the buil environment on travel behaviour,” Transportation, 45, pp. 1-23, 2017. doi: 10.1007/s11116-017-9800-4 